\title{
Biopelículas microbianas y su impacto en áreas médicas: fisiopatología, diagnóstico y tratamiento
}

\author{
Silvestre Ortega-Peña ${ }^{1,2 *}$ E Edgar Hernández-Zamora ${ }^{3}$ \\ ${ }^{1}$ Laboratorio de Infectología, Instituto Nacional de Rehabilitación Luis Guillermo Ibarra Ibarra, Ciudad de México; ${ }^{2}$ Departamento de Microbiología, \\ Escuela Nacional de Ciencias Biológicas, Instituto Politécnico Nacional, Ciudad de México; ${ }^{3}$ Servicio de Genética, Instituto Nacional de Rehabilitación \\ Luis Guillermo Ibarra Ibarra, Ciudad de México, México
}

\begin{abstract}
Resumen
Las biopelículas son comunidades de microorganismos que crecen agregados y rodeados por una matriz extracelular que ellos mismos producen, la cual favorece la adhesión covalente sobre superficies inertes y vivas; además, les ayuda a desarrollar alta tolerancia a las moléculas con actividad antimicrobiana. Por otra parte, las biopelículas se asocian con infecciones crónicas y persistentes que impactan de manera negativa en distintas áreas médicas. Además, generan altos costos a los sistemas de salud y a los pacientes cada año, porque son difíciles de tratar con antimicrobianos convencionales; adicionalmente, generan altas tasas de morbilidad y mortalidad. El objetivo de esta revisión es presentar información extensa y actualizada sobre el origen, la biosíntesis y la fisiopatología de las biopelículas, así como sobre su relación con infecciones crónicas, el diagnóstico, los tratamientos antimicrobianos actuales con actividad antibiopelícula y las perspectivas sobre la búsqueda de nuevos tratamientos. Estos últimos aún representan una importante área de investigación.
\end{abstract}

Palabras clave: Biopelículas. Infecciones crónicas. Tolerancia antimicrobiana. Diagnóstico. Tratamiento.

\section{Microbial biofilms and their impact on medical areas: physiopathology, diagnosis and treatment}

\begin{abstract}
Biofilms are communities of microorganisms that grow aggregated and surrounded by an extracellular matrix, which they produce and favors them to adhere covalently to inert and living surfaces; it also helps them to develop high tolerance to molecules with antimicrobial activity. Moreover, biofilms are associated with chronic and persistent infections, which negatively impact different medical areas since they generate high costs to health care systems and patients every year because they are difficult to treat with conventional antimicrobial drugs. Additionally, they generate high rates of morbidity and mortality. The objective of this review was to present extensive and up-to-date information on the origin, biosynthesis, and pathophysiology of biofilms. Also, its relationship with chronic infections, diagnosis, current antimicrobial treatments with antibiotic activity, and perspectives on the search for new treatments, since the latter still represent an important area of research.
\end{abstract}

Key words: Biofilms. Chronic infections. Antimicrobial tolerance. Diagnosis. Treatment.

\section{Correspondencia:}

*Silvestre Ortega Peña

E-mail: silvestreortega1265@gmail.com

DOI: 10.24875/BMHIM.M18000012
Fecha de recepción: 13-10-2017
Disponible en internet: 13-04-2018 Bol Med Hosp Infant Mex. 2018;75:79-88 www.bmhim.com

vados. 


\section{Introducción}

En microbiología, las biopelículas se definen como comunidades de microorganismos que crecen agregados y rodeados por una matriz extracelular que ellos mismos producen. La matriz extracelular está conformada por proteínas, ácido desoxirribonucleico (DNA) extracelular y exopolisacáridos (EPS) 1 . Debido al incremento de los estudios científicos en las últimas tres décadas, las biopelículas han adquirido gran relevancia, principalmente en el área médica, ya que favorecen el desarrollo de infecciones crónicas, como otitis, osteomielitis e infecciones de heridas, entre otras, y también de infecciones relacionadas con el uso de dispositivos médicos, entre ellos catéteres intravasculares, prótesis articulares y catéteres urinarios ${ }^{2,3}$.

El tratamiento y la erradicación de las infecciones causadas por microorganismos productores de biopelículas representan un gran reto debido a que estos son mucho más tolerantes a la acción de las moléculas con actividad antimicrobiana (antibióticos y antisépticos), a diferencia de los microorganismos que crecen en forma libre (planctónicos) ${ }^{4}$. Por otra parte, la matriz extracelular ayuda a que las células microbianas evadan la respuesta inmunitaria del huésped; además, los EPS de la matriz extracelular tienen la capacidad de inducir respuestas inflamatorias crónicas ${ }^{5}$.

El objetivo de esta revisión es hacer una descripción general de las biopelículas, su origen, biosíntesis y fisiopatología, así como de la relación que tienen con infecciones crónicas, el diagnóstico, el tratamiento y las perspectivas.

\section{El origen}

Las biopelículas fueron observadas inicialmente por Anton van Leeuwenhoek en 1684, cuando analizó muestras de placa microbiana obtenidas de sus propios dientes ${ }^{6}$. Años después, en 1864, Louis Pasteur también las observó en muestras obtenidas de las paredes de barriles donde se almacenaba vino; además, propuso que eran las causantes de que el vino se biotransformara en ácido acético ${ }^{7}$. A finales de los años 1980, la definición de «biopelículas» únicamente se había utilizado en microbiología ambiental, porque su formación se había observado en los tubos que transportan agua potable y en la parte inferior de los barcos, principalmente ${ }^{7}$. En microbiología médica, el concepto de biopelículas era completamente ajeno; $\sin$ embargo, en 1985, el Dr. John William Costerton (el padre de la biofilmología) trajo este concepto al área médica y propuso que muchas de las infecciones crónicas podrían ser causadas por microorganismos que estuvieran creciendo en forma de biopelículas, y que, por esta característica, los pacientes no respondían a los tratamientos antimicrobianos convencionales ${ }^{8}$.

Las investigaciones sobre biopelículas han aumentado de manera exponencial en los últimos 20 años ${ }^{7,8}$. Las primeras estuvieron encaminadas a descubrir y entender los mecanismos genéticos y moleculares que favorecen que los microorganismos crezcan en forma de biopelículas, a conocer la composición química de la matriz extracelular y a estudiar los cambios fisiológicos, morfológicos y bioquímicos que sufren las células microbianas en las biopelículas ${ }^{8}$. Los estudios más recientes están enfocados a estudiar en modelos in vitro e in vivo la patogénesis de las biopelículas ${ }^{9,10}$.

\section{Biosíntesis de biopelículas}

Desde el descubrimiento de las biopelículas se sabe que el $90 \%$ de los microorganismos poseen esta característica microbiológica, y que su biosíntesis es un proceso complejo, constante y dinámico que ocurre en cuatro fases: adhesión, agregación, maduración y disgregación (Fig. 1). En cada una de estas fases participan fuerzas fisicoquímicas y distintos mecanismos genéticos y moleculares que regulan la biosíntesis de la matriz extracelular ${ }^{11}$.

Durante la fase de adhesión ocurren dos fenómenos que favorecen que los microorganismos se depositen sobre una superficie e inicien la formación de las biopelículas: atracción y adhesión ${ }^{12,13}$. La atracción es un proceso reversible que ocurre cuando los microorganismos, en estado planctónico, son atraídos y depositados en superficies inertes mediante distintos tipos de fuerzas fisicoquímicas (Van der Waals, gravitacionales, electrostáticas, hidrofóbicas o movimientos Brownianos ${ }^{14}$. Las fuerzas fisicoquímicas pueden ser propias de las paredes microbianas 0 de las superficies inertes ${ }^{15}$. Una vez que las células microbianas se han depositado sobre una superficie, inmediatamente se inicia la fase de adhesión, la cual es irreversible. Los principales componentes que dirigen la adhesión microbiana son moléculas constitutivas de la pared microbiana: pili, flagelos, ácidos teicoicos y moléculas que los microorganismos expresan bajo circunstancias de estrés; estas últimas se denominan componentes microbianos de superficie que reconocen moléculas de matriz adhesiva (CMSMMA) ${ }^{15-17}$. Por ejemplo, la adhesión de las distintas especies de Staphylococcus sobre diferentes tipos de dispositivos 


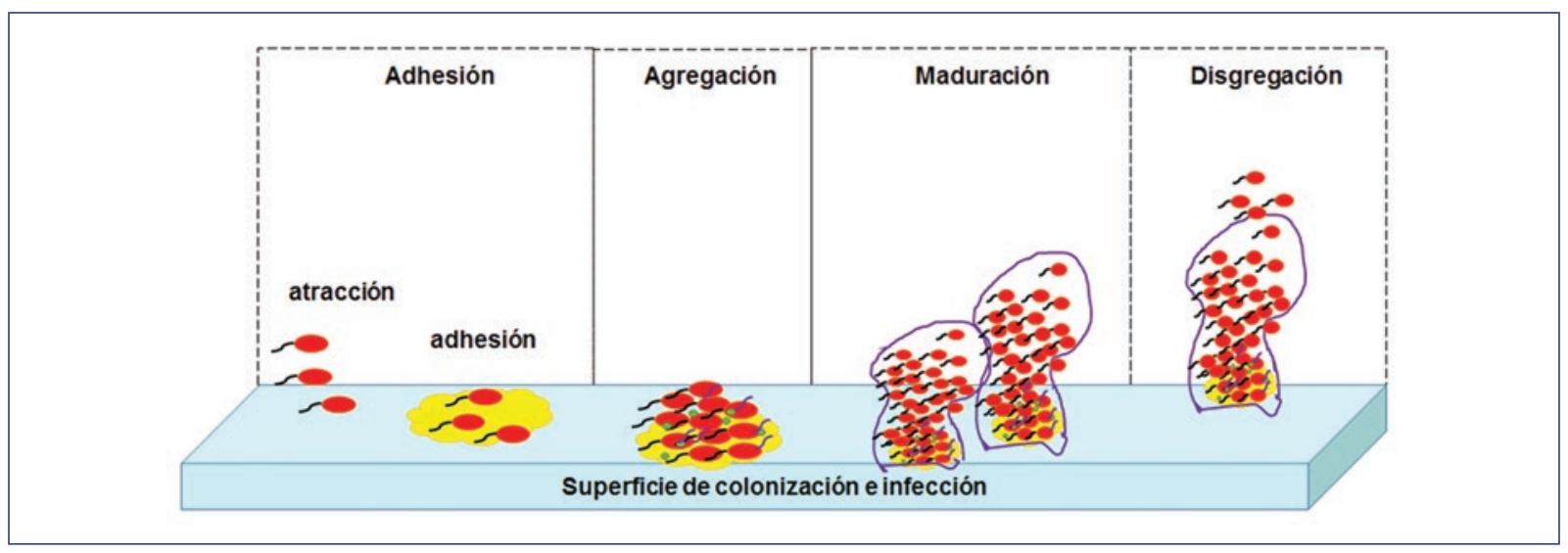

Figura 1. Proceso de la biosíntesis de biopelículas microbianas.

médicos (catéteres intravasculares, válvulas cardiacas o prótesis articulares) ocurre cuando los CMSMMA que estas bacterias poseen (proteína asociada a adhesión [Aap], proteína asociada a biopelícula [Bap], autolisina [Att] y proteína extracelular de unión a proteínas [Embp]) se unen covalentemente a proteínas de la matriz extracelular del huésped (fibronectina, fibrinógeno, elastina y colágena), las cuales recubren los dispositivos médicos inmediatamente después de ser implantados ${ }^{18-20}$.

Posterior a la adhesión se inicia la agregación, que ocurre cuando se adicionan más células microbianas a los microorganismos que inicialmente se adhirieron ${ }^{18}$. Durante la agregación se generan elevadas concentraciones de metabolitos secundarios, producto del metabolismo microbiano, los cuales son útiles para la comunicación microbiana; esta última se denomina quorum sensing $(Q S)^{21}$. El QS es un sistema de comunicación que poseen las bacterias que sirve para inducir o reprimir la expresión de genes que codifican factores de virulencia o enzimas que participan en la biosíntesis de los principales componentes de la matriz extracelular, como EPS y proteínas ${ }^{22}$.

La tercera fase es la maduración; en ella, los microorganismos que ya se han agregado comienzan a multiplicarse, a la vez que hay una excesiva producción de EPS, proteínas y liberación de DNA extracelular, que servirán para la formación de la matriz extracelular y el crecimiento de las biopelículas ${ }^{1}$. Diversos estudios han demostrado que cada especie bacteriana produce y libera EPS específicos que otorgan propiedades fisicoquímicas muy diversas a la matriz extracelular. Por ejemplo, Pseudomonas aeruginosa produce tres distintos tipos de EPS: alginato, Pel y Psl. Por otro lado, Staphylococcus spp. únicamente produce el polisacárido de adhesión intercelular, denominado también poli-N-acetilglucosamina ${ }^{23,24}$.

Adicional a la secreción de EPS, otro fenómeno que ocurre en la maduración es la liberación de DNA extracelular, que es útil para dar rigidez a las biopelículas y participa en la transferencia de genes de resistencia entre los microorganismos que se encuentran en el interior de las biopelículas ${ }^{25,26}$. Por otra parte, se forman canales de agua a través y alrededor de las biopelículas, importantes para la excreción y el transporte de las moléculas del QS. También son útiles porque ayudan al microorganismo a adquirir nutrientes del medio exterior y eliminar productos del metabolismo microbiano, que en algún momento pueden llegar a ser citotóxicos para los propios microorganismos ${ }^{21,27}$. Por último, pero no por eso menos importante, otros fenómenos que se llevan a cabo durante la maduración son los cambios morfológicos y metabólicos de los microorganismos en el interior de las biopelículas ${ }^{21,22}$.

La disgregación es la última fase en el ciclo de formación de las biopelículas, y ocurre cuando la densidad microbiana en el interior de estas ha aumentado de manera exponencial y los microorganismos en ella han generado cantidades importantes de metabolitos, los cuales ya no pueden ser eliminados a través de los canales de agua. Estos metabolitos inducen el QS, el cual a su vez induce la expresión de genes que codifican enzimas con la capacidad de degradar los componentes de la matriz extracelular ${ }^{21}$. Actualmente se sabe que la degradación es controlada por enzimas que poseen actividad DNA-asa, proteasa y fosfodiesterasa, y moléculas con propiedades surfactantes ${ }^{28}$. Todas estas ayudan a que pequeños agregados microbianos o células bacterianas se desprendan de la 


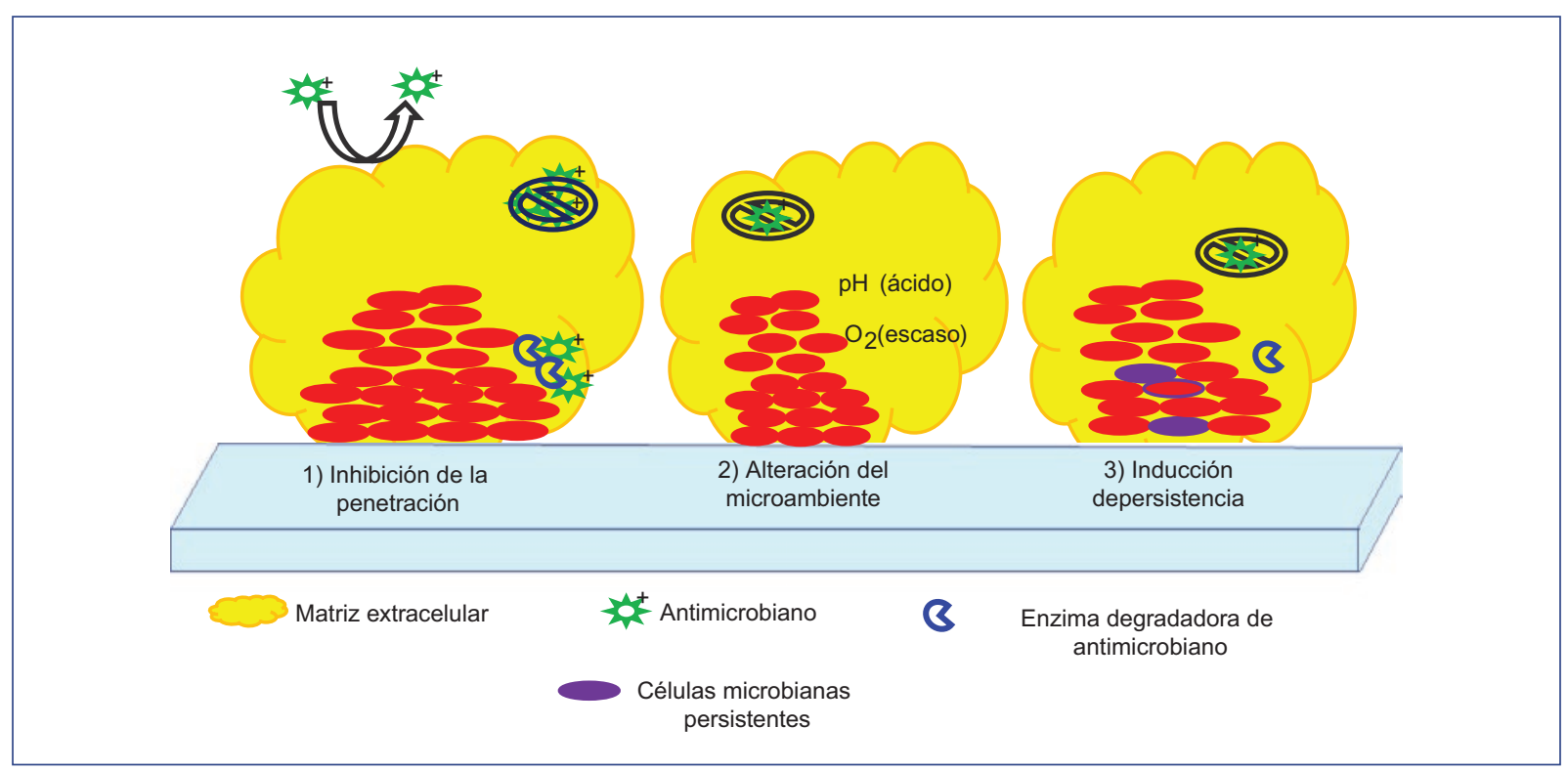

Figura 2. Fenómenos que favorecen el desarrollo de tolerancia antimicrobiana.

matriz extracelular e inicien la formación de biopelículas en una nueva superficie ${ }^{29}$. Además de las moléculas que poseen la habilidad de degradar la matriz extracelular de las biopelículas, existen otras moléculas que también disgregan biopelículas; por ejemplo, el óxido nítrico (NO) ${ }^{30}$. En $P$. aeruginosa, el NO producido por los procesos de respiración anaeróbica causa la disgregación de biopelículas formadas por esta bacteria debido a que disminuye la concentración intracelular de un segundo mensajero, denominado di-GMP cíclico, que inicia un sistema de señalización que regula el comportamiento de muchos microorganismos en su estilo de vida, haciéndolos cambiar de una vida en estado libre a biopelículas, o viceversa ${ }^{31,32}$. El papel del NO en la disgregación de biopelículas formadas por otros microorganismos de importancia clínica distintos a $P$. aeruginosa también ha sido estudiado en otros microorganismos (Neisseria gonorrhoeae, Neisseria meningitidis, Vibrio cholerae, Staphylococcus aureus, Legionella pneumophila y Escherichia coli, principalmente) $)^{30}$, y tiene el mismo efecto.

\section{Fisiopatología}

Se sabe que la patogénesis de las biopelículas radica principalmente en que son capaces de generar infecciones crónicas persistentes, difíciles de erradicar ${ }^{1}$. Lo anterior se debe a que los microorganismos que crecen dentro de las biopelículas incrementan su tolerancia a las moléculas con actividad antimicrobiana (antibióticos y antisépticos), y desarrollan mecanismos de resistencia a los antibióticos. Además, los EPS de la matriz extracelular ayudan a evadir la respuesta inmunitaria del huésped ${ }^{2,4}$.

\section{Incremento de la tolerancia antimicrobiana}

Se sabe que los microorganismos que crecen en estado de biopelículas desarrollan alta tolerancia a los antimicrobianos, hasta mil veces más, a diferencia de los que crecen en forma libre ${ }^{4}$. Este incremento se asocia principalmente con los siguientes fenómenos: inhibición de la penetración de los antimicrobianos, alteración del microambiente y formación de células microbianas persistentes (Fig. 2).

\section{INHIBICIÓN DE LA PENETRACIÓN DE LOS ANTIMICROBIANOS}

Varios estudios han concluido que las características fisicoquímicas de la matriz extracelular que rodea a las células microbianas tiene la habilidad de repeler o retardar la penetración de la mayoría de los agentes antimicrobianos que actualmente se comercializan ${ }^{4,33}$. La repulsión o el retardo se explican por las diferencias de cargas entre los antimicrobianos y la matriz extracelular. Por ejemplo, los antibióticos aminoglucósidos que poseen una carga positiva quedan atrapados entre las cargas negativas de los EPS de la matriz 
extracelular $^{34,35}$. En el caso de los antimicrobianos que penetran la matriz extracelular, esta mismas diferencias de carga pueden retardar su paso al sitio diana, haciendo que los fármacos lleguen en concentraciones subinhibitorias, las cuales son capaces de inducir respuestas de estrés en los microorganismos que favorecen la expresión de mecanismos de resistencia antimicrobiana (enzimas que degradan antibióticos, bombas de eflujo o alteraciones del sitio diana) y factores de virulencia (proteasas, toxinas, citolisinas) ${ }^{26,36}$.

\section{Alteración del microambiente}

En la parte más interna de las biopelículas, la concentración de oxígeno es baja, por lo que se genera una atmósfera anaerobia y de bajo $\mathrm{pH}$. Esto puede ocasionar una disminución en la actividad de algunos antibióticos, tales como los aminoglucósidos que disminuyen su efectividad en atmósferas anaerobias $^{37,38}$. Otros fenómenos que ocurren por las alteraciones del microambiente son la disminución del metabolismo bacteriano y la disminución de los tiempos de replicación ${ }^{37}$. Es importante recordar que el objetivo de muchos antibióticos es bloquear rutas metabólicas de los microorganismos, como la síntesis de proteínas o la síntesis de la pared bacteriana. Por ejemplo, al disminuir el tiempo de replicación, los antibióticos betalactámicos no pueden actuar de manera efectiva ${ }^{37,39}$.

\section{FORMACIÓN DE CÉLULAS MICROBIANAS PERSISTENTES}

El incremento de la tolerancia a los antimicrobianos en los microorganismos que están en el interior de las biopelículas no puede ser explicado únicamente por los fenómenos mencionados anteriormente. En años recientes se ha descrito que en el interior de las biopelículas se forman subgrupos de microorganismos con características de células persistentes ${ }^{40}$. Las células microbianas persistentes son aquellas que presentan un estado metabólico inactivo, además de que sufren cambios morfológicos que impiden la acción de los antimicrobianos ${ }^{40,41}$. El mayor problema de los microorganismos persistentes es que, cuando las biopelículas se comienzan a disgregar, estos activan de nuevo su metabolismo y migran a otra superficie, iniciando otra vez la biosíntesis de biopelículas. Además, las células persistentes, antes de dejar las biopelículas, han desarrollado resistencia antimicrobiana por la expresión de distintos mecanismos (bombas de eflujo, enzimas degradadoras), por lo que las nuevas biopelículas se formarán con microorganismos multidrogorresistentes ${ }^{4,37,42}$.

\section{Inhibición de la respuesta inmunitaria}

Además del incremento de la tolerancia antimicrobiana, otro fenómeno que ocurre en las infecciones causadas por microorganismos productores de biopelículas es la capacidad de evadir, de manera parcial o total, la respuesta inmunitaria del huésped (Fig. 3$)^{43}$. Gil, et al. ${ }^{44}$ demostraron que los EPS y las proteínas de la matriz extracelular tenían la capacidad de proteger a las bacterias contra las células y los componentes de la respuesta inmunitaria (neutrófilos, macrófagos, anticuerpos, péptidos antimicrobianos) en un modelo múrido de infección por $S$. aureus creciendo en forma de biopelículas. Estas mismas capacidades se han observado con distintos tipos de microorganismos y modelos de infección, como $P$. aeruginosa (fibrosis quística), $E$. coli y Proteus mirabilis (infecciones urinarias) ${ }^{45,46}$. Otro de los hallazgos importantes de este trabajo fue que, dependiendo de los EPS que producen los microorganismos, se pueden inducir respuestas inflamatorias crónicas $^{47}$. En un modelo in vivo de heridas infectadas en conejos con dos tipos de $P$. aeruginosa (una cepa silvestre productora de EPS y otra mutante que no producía EPS), Seth, et al. ${ }^{48}$ demostraron que la cepa salvaje inducía una mayor expresión de citocinas proinflamatorias (factor de necrosis tumoral 1 alfa e interleucina 1 beta) que la cepa mutante ${ }^{48}$. La exacerbación y la prolongación de la expresión de citocinas proinflamatorias afecta negativamente al huésped; por ejemplo, causando un retraso en el proceso de cicatrización de una herida cuando está colonizada por $P$. aeruginosa ${ }^{49}$.

\section{Infecciones asociadas con biopelículas}

Se ha mencionado que las infecciones crónicas y las biopelículas se encuentran estrechamente relacionadas. A finales de los años 1970, Hoiby ${ }^{50}$ y Lam, et al. ${ }^{51}$ describieron la colonización de los pulmones de pacientes que padecían fibrosis quística por $P$. aeruginosa creciendo en forma de biopelículas, una de las primeras infecciones que se asocia con esta característica microbiológica. Cuando analizaron biopsias pulmonares de distintos casos de fibrosis quística, los autores lo demostraron y observaron que las bacterias se encontraban incrustadas en los tejidos en forma de microagregados, y que a su vez estos estaban rodeados por una matriz extracelular ${ }^{50,51}$.

Años más tarde se reconoció que las biopelículas causaban infecciones asociadas con el uso de dispositivos médicos ${ }^{52}$. El primer reporte de este tipo data 


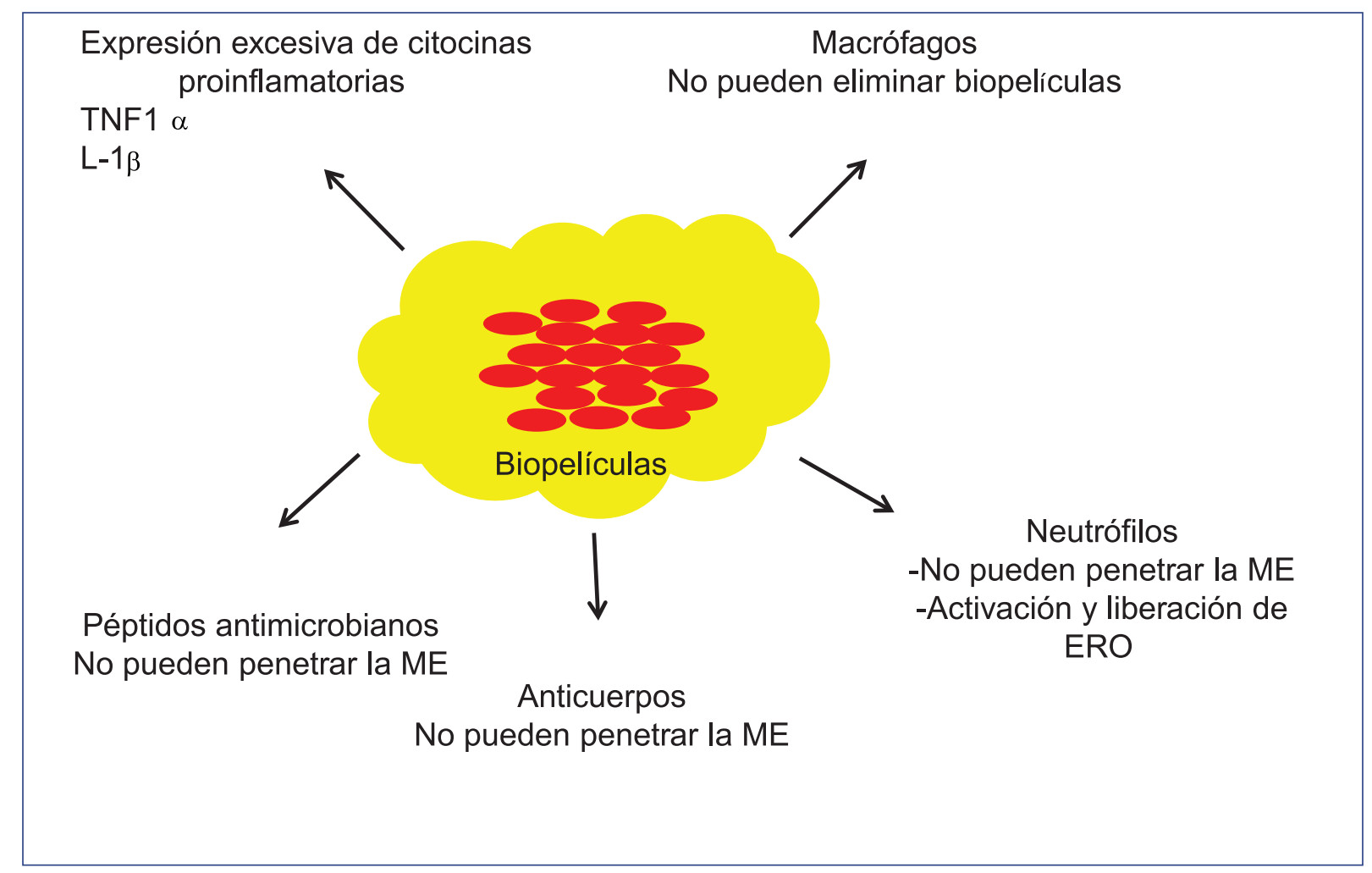

Figura 3. Biopelículas y componentes de la respuesta inmunitaria.

de 1982, cuando se analizó un marcapasos de un paciente con infección por $S$. aureus con microscopía electrónica de barrido, la cual se asoció con el uso de este dispositivo médico ${ }^{53}$. Los resultados microscópicos mostraron que la bacteria se encontraba creciendo sobre el marcapasos en forma de biopelículas ${ }^{53}$. Desde las primeras evidencias científicas en las que se encontró una relación entre la infección y la formación de biopelículas, la lista de infecciones ha aumentado de manera exponencial (Tabla 1$)^{37}$.

De acuerdo con la literatura, se estima que aproximadamente el $65 \%$ de las infecciones bacterianas son causadas por bacterias creciendo en forma de biopelículas; estas incluyen las que se asocian con dispositivos médicos y con tejidos. La incidencia cambia entre ellas, dependiendo del sitio de infección. Por ejemplo, se estima una incidencia del $2 \%$ en infecciones asociadas con implantes mamarios, del $1-4 \%$ en prótesis articulares, del $4 \%$ en válvulas mecánicas de corazón, del $10 \%$ en las derivaciones ventriculares, del $4 \%$ en marcapasos y desfibriladores, y hasta del $80 \%$ en las heridas de pie diabético ${ }^{54}$.

Por otra parte, los tipos de microorganismos que causan infecciones asociadas con implantes médicos y tejidos, y que son productores de biopelículas,
Tabla 1. Infecciones relacionadas con biopelículas

\begin{tabular}{l|l}
\hline $\begin{array}{l}\text { Infecciones en dispositivos } \\
\text { médicos }\end{array}$ & Infecciones en tejidos \\
\hline - Derivaciones ventriculares & - Otitis media crónica \\
- Lentes de contacto & - Sinusitis crónica \\
- Catéteres centrales & - Gingivitis \\
$\quad$ vasculares & - Amigdalitis crónica \\
- Válvulas cardiacas & - Laringitis crónica \\
- Marcapasos & - Endocarditis \\
- Injertos vasculares & - Fibrosis quística \\
- Implantes mamarios & - Piedras renales \\
- Tubos endotraqueales & - Infección del tracto biliar \\
- Catéteres urinarios & - Infección del tracto urinario \\
- Implantes ortopédicos & - Osteomielitis \\
- Prótesis articulares & - Heridas crónicas \\
\end{tabular}

también cambian. En las infecciones por catéteres vasculares se detectan Staphylococcus coagulasa negativos, S. aureus, P. aeruginosa, Enterobacter spp. y Klebsiella spp.; en lentes de contacto (rígidas y blandas), $E$. coli, P. aeruginosa, S. aureus, Staphylococcus epidermidis, Candida spp. y Serratia spp.; en válvulas cardiacas nativas (endocarditis), Streptococcus spp., S. aureus, S. epidermidis, Bacillus spp. y Enterococcus spp.; en catéteres urinarios, E. coli, Enterococcus faecalis, S. epidermidis, P. aeruginosa, P. mirabilis, Klebsiella pneumoniae y otros bacilos gramnegativos; en 
periodontitis, Fusobacterium nucleatum y Peptostreptococcus anaerobius; y en el pie diabético, bacterias anaerobias, hongos, $S$. aureus y $P$. aeruginosa ${ }^{37,54}$.

\section{Diagnóstico}

\section{Detección de biopelículas}

Existen diversas metodologías para la detección de biopelículas; entre ellas, las de microscopía (fluorescencia, electrónica de barrido, confocal láser), que permiten observar directamente las biopelículas sobre biopsias de tejidos infectados o dispositivos médicos contaminados $^{55}$. Sin embargo, estas pueden llegar a ser caras o complejas de realizar, por lo que su aplicación dependerá de los recursos con los que cuenten los laboratorios donde se realice el diagnóstico de infecciones asociadas a biopelículas.

En el caso de los laboratorios con pocos recursos, podrían aplicarse los métodos fenotípicos, mucho más baratos y fáciles de realizar. Estos incluyen el crecimiento en microplacas de 96 pozos con cristal violeta y la adhesión en tubo y en agar rojo congo ${ }^{56}$. La desventaja de los métodos fenotípicos es que no es posible detectar las biopelículas como tales, sino que solo se detectan los microorganismos que poseen la habilidad de producirlas; además, son métodos menos sensibles y menos específicos con respecto a los de microscopía para detección de biopelículas ${ }^{57}$.

\section{Sonicación de dispositivos médicos}

Cuando se sospechan infecciones asociadas con dispositivos médicos, puede emplearse el método de sonicación. Este método consiste en depositar el dispositivo sobre un recipiente estéril al que se adiciona solución fisiológica también estéril, y en seguida colocarlo en un baño ultrasónico a $40 \mathrm{kHz}$ durante 5 minutos $^{58}$. Posteriormente se toman alícuotas del líquido de sonicación, que se cultivan en medios de cultivo enriquecidos $^{58}$. En general, la sonicación permite desprender las biopelículas de los dispositivos médicos y cultivar los microorganismos que están causando la infección, para identificarlos y realizar pruebas de sensibilidad antimicrobiana ${ }^{58}$. De todos los dispositivos médicos, los más utilizados para cultivar los microorganismos productores de biopelículas y diagnosticar infecciones asociadas con ellos por sonicación son los catéteres intravasculares y las prótesis articulares ${ }^{58,59}$.

En las infecciones de prótesis articulares (en general causadas por biopelículas microbianas), el diagnóstico microbiológico tradicionalmente se hace mediante cultivo de muestras de tejido periprotésico (más de cinco muestras de distintos sitios). Sin embargo, en varios estudios se ha demostrado que la especificidad para identificar los microorganismos causantes de la infección es baja en comparación con el cultivo del líquido de sonicación de la prótesis ${ }^{58}$. En un estudio publicado en 2017 por Van Diek, et al..$^{60}$, en el que se compararon las metodologías antes mencionadas para el diagnóstico de infecciones asociadas con prótesis articulares, los investigadores encontraron que la especificidad del cultivo de tejidos periprotésicos fue de 0.80 (intervalo de confianza del 95\% [IC 95\%]: 0.74-0.86), mientras que el valor en el cultivo del líquido de sonicación de la prótesis fue más alto, de 0.99 (IC 95\%: 0.96-1).

\section{Ensayos de sensibilidad antimicrobiana}

Tradicionalmente, las pruebas de sensibilidad antimicrobiana en bacterias patógenas se han realizado mediante difusión en disco (Kirby-Bauer) o por la determinación de la concentración mínima inhibitoria (CMI) en caldo ${ }^{61}$. La difusión en disco y la CMI son ensayos que poseen buenas sensibilidad y especificidad para determinar la sensibilidad antimicrobiana de bacterias creciendo en forma libre; sin embargo, para microorganismos creciendo en biopelículas, los resultados no son extrapolables ${ }^{62}$. Para estos últimos, es importante realizar ensayos de sensibilidad antimicrobiana que permitan determinar la CMI de biopelículas (CMIB) y la concentración mínima de erradicación de biopelículas (CMEB), contra la cual los antimicrobianos actúan ${ }^{62}$. Por ejemplo, Schmidt-Malan, et al. ${ }^{63}$ evaluaron la actividad del tedizolid (un nuevo antibiótico para bacterias grampositivas multidrogorresistentes) en Staphylococcus aislados de infecciones asociadas a prótesis articulares, y encontraron que la $\mathrm{CMI}$ a la cual el antibiótico mataba al $90 \%$ de las bacterias en estado libre fue $<0.5 \mu \mathrm{g} / \mathrm{ml}$. Sin embargo, cuando determinaron la concentración a la que el antibiótico inhibía la formación de biopelículas (CMIB) en las mismas cepas, esta aumentó 1.5 veces $(2 \mu \mathrm{g} / \mathrm{ml})$ para terminar con el $90 \%$ de las bacterias. Finalmente, cuando los investigadores indujeron la formación de biopelículas en los Staphylococcus y determinaron la concentración a la cual el tedizolid podía erradicar el $90 \%$ de las células microbianas creciendo en este estado, encontraron una CMEB de $32 \mu \mathrm{g} / \mathrm{ml}$ (un incremento de 31.5 veces). En general, la CMIB determina la concentración a la cual los antimicrobianos tienen la habilidad de evitar que los microorganismos vuelvan a formar biopelículas después de haber estado 
Tabla 2. Antimicrobianos y antisépticos con actividad antibiopelícula.

\begin{tabular}{|c|c|c|}
\hline & Actividad antibiopelícula & Ref. \\
\hline \multicolumn{3}{|l|}{ Antimicrobianos } \\
\hline Ampicilina & Sí & 67 \\
\hline Piperacilina & Sí & 68 \\
\hline Amoxicilina-ácido clavulánico & Reducida & 69 \\
\hline Amikacina & Sí & 70 \\
\hline Gentamicina & Reducida & 68 \\
\hline Tobramicina & Reducida & 71 \\
\hline Ciprofloxacino & Sí & 67,68 \\
\hline Levofloxacino & Sí & 67 \\
\hline Ofloxacino & Sí & 68 \\
\hline Imipenem & Sí & 68 \\
\hline Cefotaxima & Reducida & 70 \\
\hline Oxacilina & Reducida & 70 \\
\hline Claritromicina & Sí & 72 \\
\hline Vancomicina & Sí & 70 \\
\hline Daptomicina & Sí & 73 \\
\hline Rifampicina & Sí & 74 \\
\hline Fosfomicina & Sí & 69 \\
\hline \multicolumn{3}{|l|}{ Antisépticos } \\
\hline Plata & Sí & 64 \\
\hline lodo povidona & Reducida & 64 \\
\hline Cadexómero iodo & Sí & 64 \\
\hline Polihexametileno biguanida & Sí & 64 \\
\hline Clorhexidina & Sí & 64 \\
\hline Ácido etilendiaminotetraacético (EDTA) & Sí & 64 \\
\hline
\end{tabular}

expuestos a los fármacos, mientras que la CMEB sirve para determinar la concentración a la cual los antimicrobianos pueden erradicar biopelículas bien establecidas y maduras, que no hayan estado en contacto previo con el antimicrobiano 62,63 .

\section{Tratamientos con actividad antibiopelícula}

A la fecha, la manera de erradicar las biopelículas sigue representando un verdadero reto debido a los cambios fisiológicos, metabólicos y bioquímicos que sufren los microorganismos cuando crecen rodeados por una matriz extracelular. No existe un tratamiento antimicrobiano que sea específico para tratar infecciones asociadas con biopelículas; de todas las moléculas antimicrobianas que actualmente se usan para el control de las infecciones, solo unas cuantas han demostrado tener la habilidad de erradicar biopelículas in vitro. Muchos de los resultados descritos hasta ahora sobre la actividad antibiopelícula son controversiales, ya que existen muy pocos estudios clínicos controlados que respalden los resultados que se han encontrado en los estudios in vitro ${ }^{64,65}$. En la tabla 2 se muestran algunos antibióticos y antisépticos con buena actividad antibiopelícula in vitro. Sin embargo, 
estos agentes deben ser empleados de manera particular, dependiendo del tipo de microorganismo que esté causando la infección, ya que se ha observado que los antibióticos o antisépticos con actividad antibiopelícula pueden perder esta propiedad frente a distintas especies microbianas productoras de biopelículas ${ }^{66-74}$. Por ejemplo, la amikacina tiene buena actividad antibiopelícula en $S$. aureus y $S$. epidermidis, pero reducida en $P$. aerugino$s a^{37}$. Para el caso del antiséptico polihexametileno biguanida, Ortega, et al..$^{66}$ encontraron buena actividad antibiopelícula para bacterias grampositivas ( $S$. aureus y $S$. epidermidis), pero baja para gramnegativas (Acinetobacter baumannii, P. aeruginosa y K. pneumoniae, principalmente). Por otra parte, diversos estudios han concluido que los antibióticos que poseen la mejor actividad antibiopelícula son la rifampicina y la fosfomicina, por lo que para el caso de los antimicrobianos con actividad reducida es recomendable hacer combinaciones con estos fármacos para mejorar la actividad antibiopelícula y optimizar los tratamientos ${ }^{64}$.

\section{Conclusiones y perspectivas}

Durante las últimas décadas, la información sobre la estrecha relación que existe entre las biopelículas y las infecciones, principalmente las infecciones crónicas, ha aumentado de manera exponencial. Como ya se describió, el tratamiento de las infecciones crónicas causadas por microorganismos productores de biopelículas sigue representando un gran reto para los clínicos, debido a que no se cuenta con un tratamiento específico que posea actividad antibiopelícula. La mayoría de los tratamientos diseñados para inhibir o erradicar biopelículas muestra buenos resultados tanto in vitro como in vivo. Sin embargo, cuando se han intentado extrapolar a la clínica, los resultados no son positivos o la evidencia científica aún no es contundente. Por ello, el diseño de tratamientos antimicrobianos con actividad antibiopelículas es un área de oportunidad para desarrollar investigación. Con el conocimiento actual sobre la fisiología de las biopelículas, deben desarrollarse tratamientos que actúen en las distintas fases de su formación para erradicar células microbianas persistentes. De esta manera, los sistemas de salud podrían ahorrarse los altos costos económicos que generan las infecciones asociadas con biopelículas, debido a los gastos de hospitalización y de tratamientos antimicrobianos prolongados, además de que, en los pacientes, se evitarían las secuelas que este tipo de infecciones pueden generar.

\section{Responsabilidades éticas}

Protección de personas y animales. Los autores declaran que para este artículo no se han realizado experimentos en seres humanos ni en animales.

Confidencialidad de los datos. Los autores declaran que han seguido los protocolos de su centro de trabajo sobre la publicación de datos de pacientes.

Derecho a la privacidad y consentimiento informado. Los autores declaran que en este artículo no aparecen datos de pacientes.

\section{Financiamiento}

No se recibió patrocinio de ningún tipo para llevar a cabo este artículo.

\section{Conflicto de intereses}

Los autores declaran no tener ningún conflicto de intereses.

\section{Bibliografía}

1. Allewell NM. Introduction to biofilms thematic minireview series. J Biol Chem. 2016;291:12527-8.

2. Bjarnsholt $\mathrm{T}$. The role of bacterial biofilms in chronic infections. APMIS Suppl. 2013;(136):1-51.

3. Romanò CL, Romanò D, Morelli I, Drago L. The concept of biofilm-related implant malfunction and "low-grade infection". Adv Exp Med Biol. 2017;971:1-13.

4. Davies D. Understanding biofilm resistance to antibacterial agents. Nat Rev Drug Discov. 2003;2:114-22.

5. del Pozo JL, Patel R. The challenge of treating biofilm-associated bacterial infections. Clin Pharmacol Ther. 2007;82:204-9.

6. Slavkin HC. Biofilms, microbial ecology and Antoni van Leeuwenhoek. J Am Dent Assoc. 1997;128:492-5.

7. Høiby N. A personal history of research on microbial biofilms and biofilm infections. Pathog Dis. 2014;70:205-11.

8. Lappin-Scott H, Burton S, Stoodley P. Revealing a world of biofilms - the pioneering research of Bill Costerton. Nat Rev Microbiol. 2014;12:781-7.

9. Lawrence JR, Swerhone GD, Kuhlicke U, Neu TR. In situ evidence for metabolic and chemical microdomains in the structured polymer matrix of bacterial microcolonies. FEMS Microbiol Ecol. 2016;92(11). pii: fiw183.

10. Xiao J, Klein MI, Falsetta ML, Lu B, Delahunty CM, Yates III JR, et al. The exopolysaccharide matrix modulates the interaction between $3 \mathrm{D}$ architecture and virulence of a mixed-species oral biofilm. PLoS Pathog. 2012;8:e1002623.

11. Ortega Peña, Franco Cendejas R. Importancia médica del biofilm de Staphylococcus epidermidis en las infecciones de prótesis articular. Invest Discap. 2014;3:106-13.

12. Peters G, Locci R, Pulverer G. Adherence and growth of coagulase-negative staphylococci on surfaces of intravenous catheters. J Infect Dis. 1982;146:479-82.

13. Peters G, Locci R, Pulverer G. Microbial colonization of prosthetic devices. II. Scanning electron microscopy of naturally infected intravenous catheters. Zentralbl Bakteriol Mikrobiol Hyg B. 1981;173:293-9.

14. Grössner-Schreiber B, Teichmann J, Hannig M, Dörfer C, Wenderoth DF Ott SJ. Modified implant surfaces show different biofilm compositions under in vivo conditions. Clin Oral Implants Res. 2009;20:817-26.

15. Hook AL, Chang CY, Yang J, Atkinson S, Langer R, Anderson DG, et al. Discovery of novel materials with broad resistance to bacterial attachment using combinatorial polymer microarrays. Adv Mater. 2013;25:2542-7.

16. Omali NB, Zhu H, Zhao Z, Willcox MD. Protein deposition and its effect on bacterial adhesion to contact lenses. Optom Vis Sci. 2013;90:557-64.

17. Becker K, Heilmann C, Peters G. Coagulase-negative staphylococci. Clin Microbiol Rev. 201427:870-926 
18. Speziale P, Pietrocola G, Foster TJ, Geoghegan JA. Protein-based biofilm matrices in Staphylococci. Front Cell Infect Microbiol. 2014;4:171.

19. Pietrocola G, Nobile G, Gianotti V, Zapotoczna M, Foster TJ, Geoghegan JA, et al. Molecular interactions of human plasminogen with fibronectin-binding protein B (FnBPB), a fibrinogen/fibronectin-binding protein from Staphylococcus aureus. J Biol Chem. 2016;291:18148-62.

20. Buck AW, Fowler VG Jr, Yongsunthon R, Liu J, DiBartola AC, Que YA, et al. Bonds between fibronectin and fibronectin-binding proteins on Staphylococcus aureus and Lactococcus lactis. Langmuir. 2010;26:10764-70.

21. Winzer K, Williams P. Quorum sensing and the regulation of virulence gene expression in pathogenic bacteria. Int J Med Microbiol. 2001:291:131-43.

22. Qin X, Sun Q, Yang B, Pan X, He Y, Yang H. Quorum sensing influences phage infection efficiency via affecting cell population and physiological state. J Basic Microbiol. 2017:57:162-70.

23. Ryder C, Byrd M, Wozniak DJ. Role of polysaccharides in Pseudomonas aeruginosa biofilm development. Curr Opin Microbiol. 2007;10:644-8.

24. Campoccia D, Montanaro L, Ravaioli S, Pirini V, Cangini I, Arciola CR Exopolysaccharide production by Staphylococcus epidermidis and its relationship with biofilm extracellular DNA. Int J Artif Organs. 2011;34:832-9.

25. Montanaro L, Poggi A, Visai L, Ravaioli S, Campoccia D, Speziale P, et al Extracellular DNA in biofilms. Int J Artif Organs. 2011;34:824-31.

26. Flemming HC, Wingender J. The biofilm matrix. Nat Rev Microbiol. 2010;8:623-33

27. Guimerà $X$, Dorado $A D$, Bonsfills $A$, Gabriel G, Gabriel D, Gamisans $X$ Dynamic characterization of external and internal mass transport in heterotrophic biofilms from microsensors measurements. Water Res. 2016;102:551-60

28. Uppuluri P, López-Ribot JL. Go forth and colonize: dispersal from clinically important microbial biofilms. PLoS Pathog. 2016;12:e1005397.

29. Cheung GYC, Hwang-Soo J, Chatterjee SS, Otto M. Phenol-soluble modulins - critical determinants of staphylococcal virulence. FEMS Microbiol Rev. 2014;38:698-719.

30. Barraud N, Kelso MJ, Rice SA, Kjelleberg S. Nitric oxide: a key mediator of biofilm dispersal with applications in infectious diseases. Curr Pharm Des. 2015:21:31-42.

31. Kim SK, Lee JH. Biofilm dispersion in Pseudomonas aeruginosa. J Microbiol. 2016:54:71-85.

32. Jenal U, Reinders A, Lori C. Cyclic di-GMP: second messenger extraordinaire. Nat Rev Microbiol. 2017:15:271-84.

33. Stewart PS. Diffusion in biofilms. J Bacteriol. 2003;185:1485-91.

34. Gordon CA, Hodges NA, Marriott C. Antibiotic interaction and diffusion through alginate and exopolysaccharide of cystic fibrosis-derived Pseudomonas aeruginosa. J Antimicrob Chemother. 1988;22:667-74.

35. Nichols WW, Dorrington SM, Slack MP, Walmsley HL. Inhibition of tobramycin diffusion by binding to alginate. Antimicrob Agents Chemother. 1988; 32:518-23.

36. Stewart PS. Antimicrobial tolerance in biofilms. Microbiol Spectr 2015;3(3).

37. Lebeaux D, Ghigo JM, Beloin C. Biofilm-related infections: bridging the gap between clinical management and fundamental aspects of recalcitrance toward antibiotics. Microbiol Mol Biol Rev. 2014;78:510-43.

38. Stewart PS, Franklin MJ. Physiological heterogeneity in biofilms. Nat Rev Microbiol. 2008:6:199-210

39. Ashby MJ, Neale JE, Knott SJ, Critchley IA. Effect of antibiotics on nongrowing planktonic cells and biofilms of Escherichia coli. J Antimicrob Chemother. 1994:33:443-52.

40. Kussell E, Kishony R, Balaban NQ, Leibler S. Bacterial persistence: a model of survival in changing environments. Genetics. 2005;169:1807-14

41. Allison KR, Brynildsen MP, Collins JJ. Metabolite-enabled eradication of bacterial persisters by aminoglycosides. Nature. 2011:473:216-20.

42. Strugeon E, Tilloy V, Ploy MC, Da Re S. The stringent response promotes antibiotic resistance dissemination by regulating integron integrase expression in biofilms. mBio. 2016;7:e00868-16.

43. Watters C, Fleming D, Bishop D, Rumbaugh KP. Host responses to biofilm. Prog Mol Biol Transl Sci. 2016;142:193-239.

44. Gil C, Solano C, Burgui S, Latasa C, García B, Toledo-Arana A, et al. Biofilm matrix exoproteins induce a protective immune response against Staphylococcus aureus biofilm infection. Infect Immun. 2014;82:1017-29.

45. Alhede M, Bjarnsholt T, Givskov M, Alhede M. Pseudomonas aeruginosa biofilms: mechanisms of immune evasion. Adv Appl Microbiol. 2014:86:1-40

46. Mauch RM, Jensen PØ, Moser C, Levy CE, Høiby N. Mechanisms of humoral immune response against Pseudomonas aeruginosa biofilm infection in cystic fibrosis. J Cyst Fibros. 2017. pii: S1569-1993:30875-5. doi: 10.1016/j.jcf.2017.08.012.

47. Clinton A, Carter T. Chronic wound biofilms: pathogenesis and potential therapies. Lab Med. 2015:46:277-84.

48. Seth AK, Geringer MR, Galiano RD, Leung KP, Mustoe TA, Hong SJ. Quantitative comparison and analysis of species-specific wound biofilm virulence using an in vivo, rabbit-ear model. J Am Coll Surg. 2012;215:388-99.
49. Scalise A, Bianchi A, Tartaglione C, Bolletta E, Pierangeli M, Torresetti M, et al. Microenvironment and microbiology of skin wounds: the role of bacterial biofilms and related factors. Semin Vasc Surg. 2015;28:151-9.

50. Hoiby N. Pseudomonas aeruginosa infection in cystic fibrosis. Diagnostic and prognostic significance of Pseudomonas aeruginosa precipitins determined by means of crossed immunoelectrophoresis. Scand J Respir Dis. 1977:58:65-79.

51. Lam J, Chan R, Lam K, Costerton JW. Production of mucoid microcolonies by Pseudomonas aeruginosa within infected lungs in cystic fibrosis. Infect Immun. 1980;28:546-56.

52. Lebeaux D, Chauhan A, Rendueles O, Beloin C. From in vitro to in vivo models of bacterial biofilm-related infections. Pathogens. 2013;2:288-356.

53. Marrie TJ, Nelligan J, Costerton JW. A scanning and transmission electron microscopic study of an infected endocardial pacemaker lead. Circulation. 1982;66:1339-41.

54. Jamal M, Ahmad W, Andleeb S, Jalil F, Imran M, Nawaz MA, et al. Bacterial biofilm and associated infections. J Chin Med Assoc. 2018:81:7-11.

55. Gompelman M, van Asten SA, Peters EJ. Update on the role of infection and biofilms in wound healing: pathophysiology and treatment. Plast Reconstr Surg. 2016;138:61S-70S.

56. Hassan A, Usman J, Kaleem F, Omair M, Khalid A, Iqbal M. Evaluation of different detection methods of biofilm formation in the clinical isolates. Braz J Infect Dis. 2011;15:305-11.

57. Mishra SK, Basukala P, Basukala O, Parajuli K, Pokhrel BM, Rijal BP. Detection of biofilm production and antibiotic resistance pattern in clinical isolates from indwelling medical devices. Curr Microbiol. 2015;70:128-34.

58. Martinez RM, Bowen TR, Foltzer MA. Prosthetic device infections. Microbiol Spectr. 2016;4(4).

59. Pérez-Zárate P, Aragón-Piña A, Soria-Guerra RE, González-Amaro AM, Pérez-Urizar J, Pérez-González LF, et al. Risk factors and biofilm detection on central venous catheters of patients attended at tertiary hospital. Micron. 2015;78:33-9.

60. Van Diek FM, Albers CGM, Van Hooff ML, Meis JF, Goosen JHM. Low sensitivity of implant sonication when screening for infection in revision surgery. Acta Orthop. 2017;88:294-9.

61. Clinical and Laboratory Standards Institute. Performance for antimicrobial susceptibility testing; Twenty-fifth informational supplement. CLSI document M100-S25. Wayne: Clinical and Laboratory Standards Institute; 2016.

62. Girard LP, Ceri H, Gibb AP, Olson M, Sepandj F. MIC versus MBEC to determine the antibiotic sensitivity of Staphylococcus aureus in peritoneal dialysis peritonitis. Perit Dial Int. 2010;30:652-6.

63. Schmidt-Malan SM, Greenwood Quaintance KE, Karau MJ, Patel R. In vitro activity of tedizolid against staphylococci isolated from prosthetic joint infections. Diagn Microbiol Infect Dis. 2016;85:77-9.

64. Percival SL, Finnegan S, Donelli G, Vuotto C, Rimmer S, Lipsky BA. Antiseptics for treating infected wounds: efficacy on biofilms and effect of pH. Crit Rev Microbiol. 2016;42:293-309.

65. Percival SL, McCarty S, Hunt JA, Woods EJ. The effects of pH on wound healing, biofilms, and antimicrobial efficacy. Wound Repair Regen 2014;22:174-86.

66. Ortega-Peña S, Hidalgo-González C, Robson MC, Krötzsch E. In vitro microbicidal, anti-biofilm and cytotoxic effects of different commercial antiseptics. Int Wound J. 2017:14:470-9.

67. Anderl JN, Franklin MJ, Stewart PS. Role of antibiotic penetration limitation in Klebsiella pneumoniae biofilm resistance to ampicillin and ciprofloxacin. Antimicrob Agents Chemother. 2000:44:1818-24.

68. Shigeta M, Komatsuzawa H, Sugai M, Suginaka H, Usui T. Effect of the growth rate of Pseudomonas aeruginosa biofilms on the susceptibility to antimicrobial agents. Chemotherapy. 1997;43:137-41.

69. Rodríguez-Martínez JM, Ballesta S, Pascual A. Activity and penetration of fosfomycin, ciprofloxacin, amoxicillin/clavulanic acid and co-trimoxazole in Escherichia coli and Pseudomonas aeruginosa biofilms. Int J Antimicrob Agents. 2007;30:366-8.

70. Singh R, Ray P, Das A, Sharma M. Penetration of antibiotics through Staphylococcus aureus and Staphylococcus epidermidis biofilms. J Antimicrob Chemother. 2010;65:1955-8.

71. Walters MC $3^{\text {rd }}$, Roe F, Bugnicourt A, Franklin MJ, Stewart PS. Contributions of antibiotic penetration, oxygen limitation, and low metabolic activity to tolerance of Pseudomonas aeruginosa biofilms to ciprofloxacin and tobramycin. Antimicrob Agents Chemother. 2003:47:317-23.

72. Yasuda H, Ajiki Y, Koga T, Kawada H, Yokota T. Interaction between biofilms formed by Pseudomonas aeruginosa and clarithromycin. Antimicrob Agents Chemother. 1993;37:1749-55

73. Stewart PS, Davison WM, Steenbergen JN. Daptomycin rapidly penetrates a Staphylococcus epidermidis biofilm. Antimicrob Agents Chemother. 2009;53:3505-7.

74. Dunne WM Jr, Mason EO Jr, Kaplan SL. Diffusion of rifampin and vancomycin through a Staphylococcus epidermidis biofilm. Antimicrob Agents Chemother. 1993:37:2522-6. 